Christina Stull, MD, MBA

Department of Internal Medicine, University of

Texas at Austin Dell Medical School, Austin, TX
Alejandro Moreno, MBBS, MPH, JD, MACP

Assistant Dean of Clinical Skills Integration and Director of

Developing Outstanding Clinical Skills Course, Departments of

Medical Education and Internal Medicine, University of Texas

at Austin Dell Medical School, Austin, TX

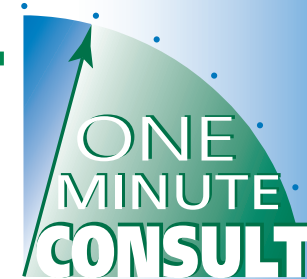

BRIEF ANSWERS

TO SPECIFIC

CLINICAL

QUESTIONS

\title{
Does this young adult patient need a hip radiograph?
}

\begin{abstract}
A A 41-year-old woman with chronic 1. L3 radiculopathy and intermittent asthma controlled with as-needed short-acting beta-agonists presents after falling from standing. She reports no new pain or changes in her low-back pain. She has no history of systemic or inhaled steroid therapy, malignancy, osteoporosis, menopause, high-force trauma, smoking, substance abuse, or debilitating disease.

She has tenderness on her lower back, but not in the hip, and is able to bear weight. Her legs are symmetric and without deformities. Her left hip demonstrates full range of motion. A straight-leg test sharply increases her radiculopathic pain. Muscle strength is preserved, except for her left hip flexors and adductors, which have $4+$ strength on a scale of 5 .
\end{abstract}

\section{HIP RADIOGRAPHY GUIDELINES LACKING FOR YOUNGER ADULTS}

Between $21 \%$ and $35 \%$ of adults fall from standing every year, and internists will inevitably encounter such patients. ${ }^{1}$ There are clinical guidelines on when a patient needs knee or ankle radiography after sustaining an injury, ${ }^{2,3}$ but there are no similar high-value care guidelines for hip films. Consequently, clinicians routinely obtain hip radiographs regardless of the patient's age, the nature of the injury, the presence of risk factors, or the physical examination findings. ${ }^{4}$

\section{RISK FACTORS FOR HIP FRACTURES}

Age and sex, as markers for osteoporosis, are the strongest risk factors for hip fracture. ${ }^{4,5}$ Hip

The authors report no relevant financial relationships which, in the context of their contributions, could be perceived as a potential conflict of interest. doi:10.3949/ccjm.87a.20011 fractures increase exponentially after age 60, with a $20 \%$ to $30 \%$ lifetime risk by age $90.5,6$ From age 60 to age 80, the hip fracture rate in women increases from 78 to 1,084 per 100,000 , and in men from 56 to 658 per $100,000 .^{5}$

On the other hand, hip fractures are uncommon in adults under age 50 , even though this group has a high frequency of injuries. A study looking at 28 million emergency room visits found only 20,000 hip fractures in patients under age 50.5

High-energy trauma, eg, from a motor vehicle accident, a fall from a height, or a sports injury such as in bicycling or ice-skating, is another risk factor for hip fracture $e^{4,7,8} ; 56 \%$ of hip fractures in patients under age 50 are from high-energy trauma. ${ }^{4,5,7,8}$

On the other hand, $90 \%$ of hip fractures in those age 60 and older occur after a fall from standing, ie, a low-energy trauma. ${ }^{5,6}$ In contrast to fractures in patients age 60 and older, most hip fractures in people under 50 are in men $(70 \%)$, reflecting the historical association between male sex and activities involving high-energy trauma. ${ }^{6-8}$

Debilitating diseases such as cancer, chronic systemic steroid therapy, heavy alcohol intake ( $>10$ drinks per week), smoking (> 1 pack per day), or substance use disorder are other important risk factors for hip fracture. ${ }^{2-4}$ White people have a higher incidence of hip fracture than other racial groups, a factor that correlates with the higher incidence of osteoporosis in this group. ${ }^{7,8}$

\section{SYMPTOMS, FINDINGS, AND INITIAL EVALUATION}

Patients with hip fracture report pain in the groin that may radiate to the knee, a phenom-
Hip fractures

are uncommon

in adults under

age 50 
enon more commonly encountered in younger patients. ${ }^{4}$ Pain in the low back, pelvis, or thigh or with a different radiation pattern indicates another process. ${ }^{4}$ All patients report exquisite tenderness when pressure is applied to the affected hip. ${ }^{4}$ Two-thirds of patients under age 50 present with a displaced fracture resulting in a shortened and externally rotated limb, inability to bear weight, and inability to move the joint in any direction actively or passively. ${ }^{2}$

Patients age 65 and older have a higher incidence of impacted hip fractures that permit joint range of motion, albeit with pain, and have no shortened, externally rotated limb, allowing for weight-bearing. ${ }^{4}$ Between $40 \%$ and $75 \%$ of patients under 50 present with hypotension or have other injuries from highenergy trauma. ${ }^{4}$

\section{DOES OUR 41-YEAR-OLD PATIENT NEED A HIP RADIOGRAPH?}

Our patient has no factors that would place her at high risk for hip fracture. She is 41 and premenopausal, has no debilitating disease, is not on chronic systemic or inhaled cortico-
Our patient

had no factors that would at high risk for hip fracture place her steroids, and does not smoke or drink alcohol heavily. Her trauma was low-energy. She re-

\section{REFERENCES}

1. Talbot LA, Musiol RJ, Witham EK, Metter EJ. Falls in young, middle-aged and older community dwelling adults: perceived cause, environmental factors and injury. BMC Public Health 2005; 5:86. doi:10.1186/1471-2458-5-86

2. Bachmann LM, Kolb E, Koller MT, Steurer J, ter Riet G. Accuracy of Ottawa ankle rules to exclude fractures of the ankle and mid-foot: systematic review. BMJ 2003; 326(7386):417. doi:10.1136/bmj.326.7386.417

3. Bachmann LM, Haberzeth S, Steurer J, ter Riet G. The accuracy of the Ottawa knee rule to rule out knee fractures: a systematic review. Ann Intern Med 2004; 140(2):121-124. doi:10.7326/0003-4819-140-5-200403020-00013

4. Walls RM, Hockberger RS, Gausche-Hill M. Rosen's Emergency Medicine: Concepts and Clinical Practice. 9th ed. Philadelphia, PA: Elsevier; 2018.

5. Kim SH, Meehan JP, Blumenfeld T, Szabo RM. Hip fractures in the United States: 2008 nationwide emergency ports no groin pain. On physical examination, the hip has normal range of motion, and the limb is not shortened, rotated, or deformed. She is able to bear weight. The subtle physical examination findings are consistent with the patient's chronic L3 radiculopathy.

For a patient such as this, a physician would have to order at least 200,000 hip films (costing about $\$ 58$ million) in order not to miss a hip fracture..$^{5-8}$ The number could be as high as 1 million hip films (\$290 million) if the patient's lack of risk factors is fully accounted for. ${ }^{5-8}$

In summary, hip radiographs should not be routinely obtained for adults under age 50 who have low-energy trauma, have no risk factors for hip fracture, have a benign physical examination, and are able to bear weight. On the other hand, plain radiography should be strongly considered for patients age 60 and older, as $90 \%$ of hip fractures in this population occur after low-energy trauma, and they can present with impacted fractures with no evidence of limb-shortening or external rotation allowing joint movement and weightbearing. ${ }^{4}$

Acknowledgment: Dr. Moreno would like to thank Timothy Weitz, JD, John Bedolla, MD, FACEP, and Patrick J. Crocker, $D O, M S, F A C E P$, for their insights.

department sample. Arthritis Care Res (Hoboken) 2012; 64(5):751-757. doi:10.1002/acr.21580

6. Al-Ani AN, Neander G, Samuelsson B, Blomfeldt R, Ekström W, Hedström M. Risk factors for osteoporosis are common in young and middle-aged patients with femoral neck fractures regardless of trauma mechanism. Acta Orthop 2013; 84(1):54-59. doi:10.3109/17453674.2013.765639

7. Karantana A, Boulton C, Bouliotis G, Shu KS, Scammell BE, Moran CG. Epidemiology and outcome of fracture of the hip in women aged 65 years and under: a cohort study. J Bone Joint Surg Br 2011; 93(5):658-664. doi:10.1302/0301-620X.93B5.24536

8. Boden SD, Labropoulos P, Saunders R. Hip fractures in young patients: is this early osteoporosis?. Calcif Tissue Int 1990; 46(2):65-72. doi:10.1007/BF02556089

Address: Alejandro Moreno, MBBS, $M P H, J D, M A C P$, University of Texas at Austin Dell Medical School, 1501 Red River Street, HLB 2.502, Austin, TX 78712.

alejandro.moreno@austin.utexas.edu 